\title{
Pragmatic annotation for a multi-layered analysis of speech acts: A methodological proposal
}

Alba Milà-Garcia, Universitat Pompeu Fabra

\begin{abstract}
Within the recently-coined sub-field of corpus pragmatics, one of the areas of interest is the study of speech acts and, specifically, how it can profit from the adoption of this methodological approach. However, the acknowledged lack of correspondence between speech acts and linguistic forms makes basic form-based corpus searches unreliable in retrieving speech acts from a corpus. In fact, function-toform corpus research can prove much more fruitful in carrying out this kind of study, but it usually requires time-consuming manual annotation, which in turn means that there have been few attempts to employ this methodology. As a contribution in this new direction, this study will showcase a function-toform approach to investigating speech acts of agreement and disagreement in spoken Catalan. Through this example, this paper aims to show the benefits of designing, compiling, transcribing and, especially, annotating one's own corpus for the study of speech acts. In order to annotate data for the study of speech acts, a complex and multi-layered annotation system was designed and manually applied, so that all the different aspects that play a relevant role in the expression of agreement and disagreement could be covered. In addition to discussing the findings from this study, it is argued that the possibilities of exploitation provided by the resulting annotated corpus far outweigh the time cost and open the door to in-depth analyses of speech acts and politeness in naturally occurring spoken data.
\end{abstract}

\section{Introduction}

Although the combination of corpus linguistics and pragmatics has been exploited for some time (e.g. Romero-Trillo 2008 and the Yearbook of Pragmatics and Corpus Linguistics series), it is only recently that it has developed into a new discipline, corpus pragmatics. The term materialized in Jucker (2013) and has subsequently had a handbook dedicated to it (cf. Aijmer and Rühlemann 2015). One of the areas that can be explored with corpus pragmatics is speech acts. The studies that have focused on these so far have followed three main directions: a diachronic perspective (e.g. García McAllister 2015), a synchronic perspective (e.g., Kohnen, 2015) and the development of (semi)automatic speech act annotation (Weisser 2003,2015 ) that can pave the way for the analysis of bigger samples. Although (semi)automatic speech act annotation keeps improving, manual annotation is still needed in order to carry out in-depth analyses of speech acts that aim to go beyond the search for speech act verbs with specific linguistic structures. However, manual annotation requires researchers to have a deep knowledge of the corpus data, or to compile it themselves, but choosing the latter will have a direct impact on the scale of the corpus (the larger it is, the longer it will take to annotate). Despite the (actual) drawbacks associated with manual annotation, this paper aims to emphasize the great value of this methodological approach. It is hoped to show how it can contribute to speech act and politeness research. The benefits of manual pragmatic annotation are exemplified through the compilation, transcription, annotation and analysis of a spoken corpus of agreement and disagreement in Catalan that combines three different discourse genres: casual conversations, meetings held in academic contexts and professors' office hours. This paper takes a 
function-to-form approach to the study of speech acts and central to this is the careful design of the corpus and annotation system (as detailed below).

\section{Corpus design for the study of agreement/disagreement}

According to Kasper and Dahl (1991), research instruments are one of the main causes of variation in pragmatic studies, together with sociolinguistic elements. Discourse completion tests (DCTs) and role plays have amassed a long tradition in pragmatics, but the combination of pragmatics with corpus linguistics turns the use of naturally-occurring discourse into a basic requirement. Once a corpus is compiled or obtained, corpus linguistics can be brought in as a methodological tool (O'Keeffe and Walsh 2012: 161), in order to lead to "greater depth of analysis in combination with another theoretical framework". The quantitative nature of corpus linguistics can be combined with different frameworks which focus on a qualitative approach, such as conversation analysis (e.g. Santamaría-García 2011; Walsh, Morton and O'Keeffe 2011), discourse analysis (e.g. Santamaría-García 2011) and pragmatics (e.g. Santamaría-García 2011; Haugh and Chang 2013).

Research in pragmatics has previously searched for a way to benefit from the large collections of text provided by big corpora (Geluykens and Craft 2008), which offer the possibility to work with a volume of data that pragmatics usually cannot attain. However, the sheer size of these corpora proves to be a problem in itself for different reasons. Firstly, since they were not meant to be used for pragmatic analyses, the design behind them does not account for, nor include, the type of information that is fundamental to the study of pragmatic phenomena: especially sociolinguistic and contextual information. ${ }^{1}$ Secondly, despite their size, these corpora might not contain a sufficient number of the specific trait under study, or, on the contrary, there might be just too many cases (something that can prove to be problematic depending on the research goal). Finally, even though large corpora are usually grammatically annotated, this kind information might not be relevant to researchers and they may need to annotate these corpora again with the information their study requires.

With these problems in mind, there has been an emergence of small corpora, since they can reach a depth of analysis that large corpora cannot provide. In small corpora studies, corpus design is tailored specifically to the research question; consequently, the resulting corpus offers plenty of cases for analysis and all the metadata that is required to interpret them and make correct assumptions. Researchers can review all of these instances (Clancy and O'Keeffe 2015) and their analysis can take into account even those items that have a very low frequency but that are still relevant and can provide information about the interaction. Moreover, small corpora are "eminently suitable for investigating phenomena in context given the constant interpretative dialectic between features of texts and the contexts in which they are produced" (Vaughan and Clancy 2013: 70). In fact, since in these studies researchers are often also compilers, analysts and even participants (Clancy and O'Keeffe 2015), they have a more extensive knowledge on the participants and the situational context, which serves to add a qualitative value to (what could otherwise be limited to) quantitative results (Koester 2010). 


\section{Defining the corpus and the subcorpora: three discourse genres ${ }^{2}$}

According to McCarthy (1998), the compilation of spoken corpora can follow two different approaches: the demographic approach and the genre approach. In the latter, put forth by Crowdy (1993) as contextgoverned corpora, samples are chosen according to the situational parameters of the interaction that define discourse genres, so that the full range of linguistic variation found in spoken language in a specific discourse genre can be covered (Ballester, Marcos-Marín and Santamaría-García 1993; McCarthy and O'Keeffe 2008). This approach selects the samples for the corpus, taking into account not only the speakers, but also the context and the situation in which interactions take place. An example of this approach is the Cambridge and Nottingham Corpus of Discourse in English (CANCODE) (McCarthy 1998). Out of the five contexts based on the type of relationship between participants that were established for CANCODE, this study includes four of them: professional, which takes place among professionals in a professional context; pedagogical, which takes place in an educational context; socialising, which focuses on social activities and is the most common in daily life; and intimate, which takes place among family of close friends.

This study focusing on agreements and disagreements, sought to cover the four relationship types, across three discourse genres. Firstly, the intimate and socialising relationship types are in play in conversations among friends and family. Secondly, one of the best contexts in which agreement and disagreement take place, and which covers the professional relationship, is meetings. According to Holmes and Stubbe (2003: 64, based, in turn, on Dwyer 1993), their main functions are planning, informing and problemsolving, activities which require a constant search for agreement among their participants (Ehlich and Wagner 1995). Most of the meetings in the corpus were held in academic contexts, some at university (among members of research groups and teaching fellows) and some at school (among teachers, sometimes including the principal). Finally, concerning the pedagogical context, university office hours prove to be a valuable resource. They bring about the interesting possibility of introducing a difference in status between the student and the professor which clearly affects the way in which they express agreement and disagreement. In this sub-corpus, office hours have a specific and conflictive goal: the students meet with the professors in order to discuss and agree on a mark for their final assignment. Besides the fact that these discourse genres cover the four relationship types established in McCarthy (1998), they were also chosen because they were seen as fruitful sources of agreement and disagreement between participants. 
The main features of these three genres are described in table 1:

Table 1. Situational and discursive features of the genres

\begin{tabular}{llll} 
& Conversations & Meetings & Office hours \\
\hline Goal & interpersonal & transactional & transactional \\
Topic & daily life & specialised & specialised \\
Frame of interaction & quotidian & institutional & institutional \\
Planning & no & yes (topic) & yes (topic) \\
Speaker's control of their & low & medium/high & high \\
linguistic production & & & \\
Status of the participants & equal & equal / unequal & unequal \\
Distance among the & & & distance \\
participants & proximity & \pm distance & \\
\hline
\end{tabular}

As can be seen, there is virtually no shared trait between conversations, on the one hand, and meetings and office hours, on the other. The divergence starts at the very purpose of the interactions: while conversations are used to socialise with other speakers in order to sustain and enhance interpersonal relations, both meetings and office hours are held in order to achieve specific goals, and are therefore transactional in focus. However, even between meetings and office hours, there are notable differences, such as the number of participants and the unequal status among the participants, which is always present in the office hours but depends entirely on the presence of a superior (boss, chief, manager, etc.) in meetings. According to the face systems devised by Scollon, Scollon and Jones (2012, first established in Scollon and Scollon 1995), based on the power (P) and the distance (D) among participants, conversations are a clear example of the solidarity face system $(-\mathrm{P},-\mathrm{D})$ and office hours follow a hierarchical face system $(+\mathrm{P},+\mathrm{D})$. Meanwhile, meetings are a combination of a hierarchical face system if a superior is in attendance, but it becomes a system of deference $(-P,+D)$ if all the members share the same status. The importance of distance cannot be understated, since, according to Holmes and Stubbe (2003: 53) meetings always have two main goals: "getting things done efficiently while constructing and maintaining collegial relationships".

There is a final shared trait between meetings and office hours that must be taken into account: they are instances of institutional talk, and therefore they share the three elements established by Drew and Heritage (1992) regarding this kind of interaction: the interaction is structured around specific goals or tasks that are linked to the participants' institutional identity; there are restrictions concerning the kind of contributions participants can make and the interaction is associated with certain frames and procedures that are specific to each institutional context. Therefore, the comparison of these three genres can prove to be interesting from many different points of view. 


\section{Data collection}

Following the design described above, a corpus was compiled: the Corpus d'Acord i Desacord en Català ('corpus of agreement and disagreement in Catalan,' CAIDAC). Table 2 shows its main features:

Table 2. Summary of general features of CAIDAC

\begin{tabular}{lllllll}
\hline & \multicolumn{7}{c}{$\begin{array}{l}\text { Length of } \\
\text { agreement }\end{array}$} & $\begin{array}{l}\text { Agreement } \\
\text { and } \\
\text { sumber of }\end{array}$ & $\begin{array}{l}\text { Total } \\
\text { samples }\end{array}$ & length & $\begin{array}{l}\text { and } \\
\text { disagreement } \\
\text { disagreement } \\
\text { sequences }\end{array}$ & Turns & Words \\
& & & & & \\
\hline Conversations & 10 & $11: 40: 10$ & $1: 50: 13$ & 361 & 2,835 & 24,524 \\
Meetings & 7 & $8: 59: 46$ & $3: 00: 22$ & 488 & 4,630 & 36,105 \\
Office hours & 20 & $6: 42: 38$ & $1: 02: 13$ & 162 & 979 & 13,773 \\
TOTAL & $\mathbf{3 7}$ & $\mathbf{2 7 : 2 2 : 3 4}$ & $\mathbf{5 : 5 2 : 4 8}$ & $\mathbf{1 , 0 1 1}$ & $\mathbf{8 , 4 4 4}$ & $\mathbf{7 4 , 4 0 2}$ \\
\hline
\end{tabular}

The data in table 2 show that the number of samples differs according to genre. This decision was made in an effort to balance out the final number of agreement and disagreement sequences and, especially, of words and turns found in each of them. The disparity is due both to the features of each genre and to the frequency of appearance of agreement and disagreement: even though conversations and meetings usually lasted for one hour, agreement and disagreement were more frequent in meetings, because they are goaloriented and focus on problem-solving, and therefore fewer samples were needed. On the other hand, office hours rarely extended over fifteen minutes, and agreement and disagreement arose at very specific moments; consequently, the number of samples had to be increased in order to attempt to increase the number of words, turns and sequences.

Data collection was carried out in two different ways. In some cases, the researcher was present and participated in the recording, which meant that the pertinent sociolinguistic information was obtained directly from the participants. In most cases, however, the researcher was absent and one of the participants was asked to record the interaction and obtain the necessary information instead. This was the case for most of the meetings and all of the office hour encounters, since only the designated participants could attend them. All participants signed a consent form, which stated that their identity would be protected by replacing both their names and all the external references they made by pseudonyms. Concerning the period of data collection, most of the recordings were made between December 2012 and March 2014, except for 14 office hour samples, which were recorded between 2006 and 2009 and which were shared by a professor who had conducted a previous study on this discourse genre from a different perspective.

\section{Participants}

The speakers in the corpus were born and lived in the region of Barcelona, and they all have Catalan as their mother tongue. ${ }^{3}$ Figure 1 shows the gender and age distribution of the 104 speakers that are part of the corpus: 


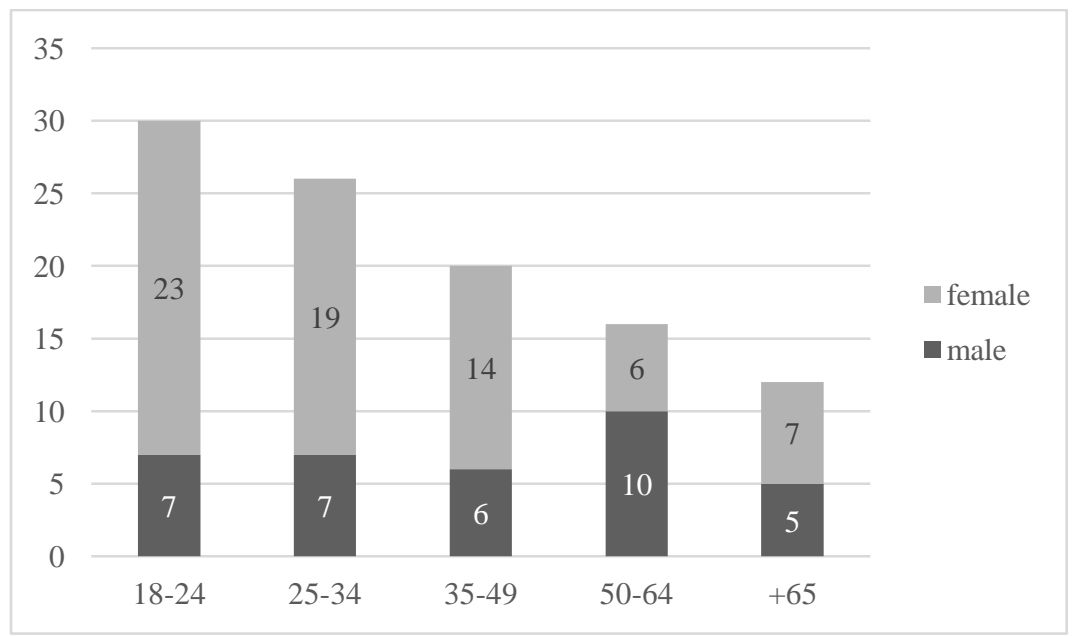

Fig. 1 Gender breakdown by age in CAIDAC

As seen in figure 1, the 18-24 age range comprises the most participants, a fact that is due to the need to record a higher number of office hours in order to compensate for their shorter length. Since the students are always different, there are a lot of speakers in this age range: 18 to 24 years old. On the other hand, the professors are the same in some samples, and therefore the increase in the number of samples is not reflected as clearly in any other age range. Regarding the age range with fewer speakers, +65 year-olds, it reflects the fact that in Spain people are usually retired at that age, and they therefore only appear in the conversation recordings.

There are more women in two out of the three genres, a fact that is due to two different factors. In the case of the 18-24 age range, the office hours were compiled at a Translation and Interpreting Department where more than $80 \%$ of the students are females. This fact also applies to the professors' gender. As for the 25-34 and the 35-49 range, a significant number of speakers are teachers participating in educational meetings at school, a context where females are also more represented. Regarding all the participants, sociolinguistic information was gathered in order to annotate the corpus and prepare it for qualitative analysis of the data.

\section{Transcription}

As with many other aspects of research, the theoretical objectives define the transcription system that will be used for a study. In order to work on individual projects such as this one, one can adopt a system designed ad hoc as long as its use is consistent. However, it is always advisable to base it on established conventions so that it is easier to share the results with other languages and traditions. Among the different existing transcription systems, DuBois' discourse transcription (DuBois 1991, a system subsequently updated in a document available online) was chosen, a decision made according to the research project's objectives, as suggested in Adolphs and Knight (2010: 41). Moreover, this system was deemed appropriate because it was also used in the two largest existing spoken corpora of Catalan: the Corpus Oral de Conversa Col·loquial (Spoken Corpus of Colloquial Conversation) (Payrató and Alturo 2002) and the Corpus Oral de Registres (Spoken Corpus of Registers) (Alturo et al. 2004). 


\section{A multi-layered annotation system}

Corpus annotation is generally considered an added value (McEnery, Xiao and Tono 2006), since it provides additional information about the original text and eases and expands the search possibilities that the corpus can undergo. Although POS tagging is widely used and its automation has reached a high accuracy, pragmatic annotation is much more complex, especially when it comes to the study of speech acts, since they are not unequivocally represented by a specific set of linguistic features (Garcia McAllister 2015), but are actually very variable instead. Jautz (2008: 147) observes that "it is difficult to investigate phenomena above the level of the word or phrase in corpora [...]. Since corpora are not yet tagged for speech acts, it is not possible to search for all instances of gratitude in a speech act theoretical sense." A search based on the forms gratitude usually takes could potentially find many explicit expressions of gratitude, but, as Garcia (2015) points out, "nonconventional indirect speech acts are essentially unsearchable," and would therefore remain undetected.

So far, only semi-automated tools have been developed for pragmatic annotation (see, among others, Weisser 2015), which focus on identifying the different types of speech acts according to Searle (1976): representatives, directives, commissives, expressives and declaratives. Therefore, if the researcher has a more in-depth analysis in mind, manual annotation seems to be necessary and recommended (McEnery, Xiao and Tono 2006). If this kind of annotation is properly applied to a whole corpus, "no speech acts and manifestations of speech acts can be missed" (Kohnen 2015: 64), since researchers must conduct a thorough revision in order to identify and annotate all the cases of the speech act under study. When researchers decide to manually annotate a corpus with pragmatic information, a whole world of possibilities opens in front of them, since any element can be tagged. However, the complexity of the annotation scheme will be closely linked to the time and effort it will take to prepare the corpus for the subsequent analysis. This might be the reason why manual pragmatic annotation in corpora is usually limited to tagging segments with the most basic classification of speech acts (Kallen and Kirk 2012; Kirk 2016), namely Searle's (1976), or with the types that could be found in one of Searle's categories, such as Ronan's (2015) study of expressive speech acts. In fact, one of the few studies that delves further into speech act realisation is Culpeper and Archer's (2008) sociopragmatic corpus, which focuses on the different manifestations of requests following a diachronic approach. In pragmatics, this kind of meticulous analysis of the different manifestations of speech acts is usually applied to data obtained by other research methodologies, such as DCTs or role plays, since the stretches of languages they provide are usually shorter and less complex than those of naturally-occurring discourse.

This type of detailed classification can be difficult to apply if they contain too many categories, since they generate doubts and make annotation even more time-consuming; therefore, researchers must decide from the beginning which elements are compulsory for the analysis: "there is a necessary balance in any categorisation between usefulness and ease or consistency of coding" (Archer, Culpeper and Davies 2008: 631). All the selected categories must be justified and clearly defined, since annotation is, after all, the researchers' interpretation of the data, and therefore the process that was followed to reach this interpretation must be clearly stated (Leech 1993). In order to carry out an in-depth analysis of agreement 
and disagreement in Catalan, the annotation, in the present study, had to cover many different aspects. Five layers were established, which were concerned with different dimensions of the data, and applied using UAM CorpusTool (O'Donnell 2008). They will be presented briefly in the following sections in order to demonstrate their purpose, but for a detailed explanation of the categorisation used in this study, see Milà-Garcia (2017). In order to illustrate how these layers were coded, the following example of a disagreement sequence will be used:

Conversation 5, sequence 11. Four long-time female friends are having dinner at a restaurant.

MAF: Està una mica massa fet, l'ou.

This egg is over-cooked.

EAF: $\quad(1,6)$ Depèn de com t'agradi, clar.

It depends on how you like it, though.

MAF: (2) Ha d'estar casi cru!

It should be almost raw!

EAF: $\quad$... Ja, per fer-ho -- ja.

Yeah, in order to make it -- yeah.

The English translation and additional examples are found in the Appendix 1 to illustrate each layer of annotation.

\section{Situational information}

This layer concerns the most basic details relating to each of the samples. On the one hand, it establishes the discourse genre of the sample, the relationship type according to the CANCODE classification, the number of participants, the time and the place. On the other hand, this layer offers information that is closely linked to the interaction, following Eggins and Slade's (1997) proposal for the analysis of casual conversation, which has been followed in the compilation of other corpora (Santamaría-García 2011: 354). These authors establish four variables for the register variable of tenor, which focuses on interpersonal meanings: status relations, affective involvement, contact and orientation to affiliation. Besides the contextual information these categories can bring to the interpretation of the different phenomena found in the data, they are also related to the situational factors that condition the use of politeness, thus being very helpful in the analysis of the presence or absence of face-saving mechanisms in each situation (see appendix 1.1).

\section{Speaker information}

In order to analyse a specific interaction among a number of participants, each turn must be labelled with the corresponding information (Archer 2005). In addition to the creation of a specific label to identify each speaker, the annotation also states their gender, age, level of education, role and status in a specific sample (see appendix 1.2). While the first three refer to basic sociolinguistic information, the last two play a more essential role in the manifestation of disagreement, since they are directly related to power. In relation to role and status, power and distance (established in the situational information layer as affective 
involvement) must be considered, and they are, in fact, two of the micro-factors with which variational pragmatics is concerned. Although this branch of pragmatic research is primarily focused on variation among language varieties, their ultimate goal is to combine both micro and macro dimensions (Schneider and Barron 2008); therefore, corpus pragmatics could prove to be a valuable frame in which this union could take place.

\section{Sequence information}

This global layer is designed specifically to define the beginning and the end of every case of agreement and disagreement (see appendix 1.3). A sequence starts with an initiation, which is followed by the speech act (or acts, in multi-party interactions) that can be accompanied by different supportive moves and which may end with an explicit closing strategy. Thanks to this layer, researchers can determine which elements in the pragmatic or interactional annotation scheme can be found in each type of sequence. They enable the recovery and comparison of the tags that are used in each type of sequence. For example, researchers are able to establish if a specific speech acts favours the use of direct or indirect acts, they can compare the length and complexity of the sequences and, basically, they can study the realization of agreement and disagreement as a whole from a discursive perspective, thus finally moving beyond the adjacency pair (Edmondson 1981: 55).

Although sequences are commonly used as a unit of analysis in pragmatics (e.g. Blum-Kulka, House and Kasper 1989; Scott 2002), they are seldom clearly defined and there can be some differences in the way they are conceived according to the author. For the annotation in this study, a new sequence always starts with an initiation turn, which in turn gives rise to a reaction, which can be agreement or disagreement, from an interlocutor. Once there is a change or topic, an interruption or another major change, the sequence finishes. The use of sequences as a unit of analysis provides a new feature that can be subject to analysis, which can then be combined with other features such as discourse genre, speaker information (gender, age, role, etc.) or even type of head act.

\section{Interactional information}

In recent years, conversation analysis has started to be combined with corpus linguistics (e.g., Santamaría-García 2011, Clancy and McCarthy 2015), and it has currently become another possible layer in the annotation of corpora (Yang 2014. Thus, its scope, which used to be distinctively qualitative, can now be widened to include a quantitative dimension. Conversation analysis was needed for this study due to the fact that disagreement has received quite a lot of attention in this discipline: Pomerantz (1984) initially claimed that disagreement was a dispreferred second pair part but her claim has been challenged by authors such as Kothoff (1993), Brenes Peña (2011) and Santamaría-Garcia (2011). As established by

Pomerantz (1984) specifically for disagreement and by other conversational analysts such as Schegloff (2007), the main interactional feature that defines a dispreferred second pair part is an initial delay; therefore, both inter-turn gaps and turn-initial delays (external gaps) have been annotated in the corpus in order to reveal whether disagreement in the CAIDAC is presented as a preferred or a dispreferred second pair part. Moreover, overlaps and interruptions have also been included: their value is defined in each 
appearance (to agree, to disagree, neutral) in order to see how they are used in the expression of each speech act (see appendix 1.4). The inclusion of this layer in the annotation scheme will undoubtedly depend on the research goals and the speech act under study.

\section{Pragmatic information}

This layer is devoted to the annotation of the speech acts of agreement and disagreement. In this study, these reactive speech acts are understood as two sides of the same coin: they offer two different and mutually exclusive reactions that can be given by the speaker in response to a previous intervention. In the case of agreement, the speaker shares the same point of view regarding the "evaluation of a situation [or] the expression of a personal judgement" (Atelsek 1981: 221) as the previous speaker, while in the speech act of disagreement, the speaker's point of view diverges from that of the previous speaker. The speech acts of agreement and disagreement are the main categories in the pragmatic layer, but the discursive perspective adopted in this study demands a holistic perspective that covers the whole realisation of agreement and disagreement, which extends beyond and is much more complex than the simple speech act. Therefore, tags were created in order to include other pragmatic elements into the analysis, such as the different kinds of initiation that can trigger the appearance of agreement and disagreement or the different ways in which they can finish.

The pragmatic layer is firstly divided into the different components that play a role in the expression of agreement and disagreement, and then these categories are divided into different and more specific ones. These manifestations are intended to have a functional rather than linguistic justification, and they have been established through the observation of the corpus and previous research on the topic. The first extensive project that designed a clear-cut taxonomy for the study of speech acts is the Cross-Cultural Speech Act Research Project (CCSARP) (Blum-Kulka et al. 1989), whose objective was the study of requests and apologies in eight different languages (American English, British English, Australian English, Canadian French, Danish, German, Hebrew and Russian) through the use of a discourse completion test. This sociopragmatic taxonomy has been reproduced in many subsequent studies of requests and adapted for the study of other speech acts. Besides the taxonomies that have derived from this project, many authors have brought forward different classifications for the study of disagreement (Muntigl and Turnbull 1998; Rees-Miller 2000; Locher 2004; Santamaría-García 2005, among others).

Therefore, there is a strong starting point from which an extensive taxonomy for the study of agreement and disagreement can be developed in combination with the observation of the corpus. Its categories must be specific but, at the same time and whenever possible, general enough so that they can be applied to the study of other corpora or even different speech acts. The main categories that were used in this study are an adaptation of the CCSARP proposal. Firstly, there are head acts, which are the smallest unit that can carry out the speech acts (agreement and disagreement). These head acts can be manifested in three different ways (direct speech acts, conventional indirect speech acts and nonconventional indirect speech acts) and are then subdivided into specific manifestations. These head acts can contain, be preceded or be followed by supporting moves, which modify the head act's illocutionary force, either reducing it, via 
mitigators, or enhancing it, via aggravators. Since agreement usually presents a very simple structure, these supportive moves are mostly present in disagreement, which is much more complex: originally it was considered as face-threatening acts (Brown and Levinson 1987), and although this claim has been challenged (Angouri and Locher 2012), their realisation usually involves a lot of facework. Another main category that is used almost exclusively in disagreement sequences is closing, that is, the different ways in which this speech act can be brought to a (satisfactory) close. Finally, both speech acts react to an initiation, that is, the different ways in which a sequence can start, via a statement, an assessment, a proposal, etc. Additionally, a category reserved for others had to be created, in order to annotate the realisations that do not contribute actively to the agreement or disagreement that is being expressed but that contribute to the development of the sequence.

All these categories are then broken up into more specific manifestations that reveal how these speech acts are composed and enacted in real interaction. (see appendix 1.5) The resulting classification is informed by both previous research and, in a bottom-up manner, by the close observation of the corpus and the speakers' interventions. It is also through close observation of the discursive context that researchers are able to identify and annotate the different elements in the data: in the case of the speech acts of agreement and disagreement, their identification as such must rely greatly on the perlocutionary force behind them. Therefore, researchers must take into account whole stretches of text to see the participants' reactions in order to be able to annotate these speech acts and to interpret and evaluate them as (im)polite (Locher and Watts 2005).

\section{Results and discussion}

Once the corpus has been compiled and annotated according to the objectives of the study, it is ready to be exploited. The simplest way to start the analysis is to recover all the instances of use of a specific tag using a KWIC (key word in context) search, a function that was also available in the annotation tool UAM CorpusTool. Considering the type of annotation that was introduced in the corpus, the resulting concordance line will not display a word, but a pragmatic tag. As an example, figure 2 shows the concordances for the tag hedges, which, in the corpus, referred to discourse markers that appeared at the beginning of a disagreeing turn in order to mitigate its illocutionary force: 


\begin{tabular}{|c|c|c|c|}
\hline File & Pretext & $\langle$ Pragmatics feature="hedge"|> & PostText \\
\hline Converses/C1.txt & an dos pots, eh? & Bueno, & ens la mengem \\
\hline Converses/C1.txt & menjat tan ràpid? & Home, & és que .. els \\
\hline Converses/C1.txt & menja. No, no. & A veure & en un princi \\
\hline Converses/C1.txt & rincipi no són-- & Bueno & cadascú que me \\
\hline Converses/C1.txt & ensèriol .. No, & home, & clar que no! \\
\hline Converses/C1.txt & Es diu Albert -- & Home, & a mi també em \\
\hline Converses/C1.txt & nt clara, no? & Home & , espero.... (1 \\
\hline Converses/C1.txt & ue faci olor/ - & Buenol. & no sé -- \\
\hline Converses/C1.txt & ets alèrgic, sí. & Home, & si ets alèrgic \\
\hline Converses/C1.txt & si ets alèrgic $=\ldots$ & Bueno, & vale, però vu \\
\hline Converses/C1.txt & també va bé, eh? & Clar, & si serà això. \\
\hline Converses/C1.txt & allà, està buit. & Avera -- & Que això \\
\hline Converses/C1.txt & = blaven poques. & Bueno, & no sé, ja que \\
\hline Converses/C1.txt & gur que en porta. & Home -- & $\mathrm{ja}=$ (1) $\mathrm{P}$ \\
\hline Converses/C1.txt & de súplica)) No, & home, & no! No ... n \\
\hline Converses/C1.txt & e la van regalar. & Home, & molt molt maca \\
\hline Converses/C1.txt & ar, vull dir $=$ & Home, & clar. Algú \\
\hline Converses/C1.txt & ... Si, si, si. & Home, & si et poses to \\
\hline Converses/C1.txt & a marxa un núvol .. & bueno &..- No, $n$ \\
\hline Converses/C1.txt & ran pel costa $=\mathrm{t!}$ & A veure & senyors exag \\
\hline Converses/C1.txt & cosa és que la - & Home, & però pobres ho \\
\hline Converses/C1.txt & Europa League -- & Bueno, & la supercopa \\
\hline
\end{tabular}

Fig. 2 Concordance lines for the tag hedge

As shown in figure 2, concordance lines are presented according to the tag query, and some of the text surrounding them can be seen. Just as in any other corpus, by clicking on the main tag it will be shown in context in the source file. This type of vertical reading (Aijmer and Rühlemann 2015) is particularly useful with short pragmatic tags, such as discourse markers. Otherwise, if the tag that is being recalled contains many words that take up the whole concordance line, the visual help that this method is intended to provide is lost. This method is particularly useful for retrieving all the forms that can manifest for any specific function which has been tagged. In other words, it offers a ready retrieval of forms for any pragmatic function that has been tagged. In Catalan, for example, figure 2 shows that the main hedges are bueno, a veure (or avera) and home; the pragmatic value of these three particles is similar to that of well. More than 500 instances of hedges were recovered in total, which can thereafter be sorted by other variables such as discourse genre, speaker (and, further, by age, gender, studies, etc.) and by the type of disagreement they modify.

Besides this function, pragmatic annotation can be used to retrieve raw counts of the different elements in the corpus in order to carry out a quantitative analysis. Researchers can obtain these counts separately for the different pragmatic tags, but they can also carry out specific searches by applying the categories from the five different levels of annotation as filters. On the one hand, they can recover every single instance of disagreement; on the other, they can limit the results to cases of direct disagreement that has been uttered by a speaker with a superior status in a meeting in overlap with the preceding utterance. All the instances that are recovered after applying these filters can then be analysed individually and in context, thus allowing for the qualitative analysis that usually defines pragmatics or, as Aijmer and Rühlemann (2015) call it, the horizontal reading.

This section aims to show several ways in which the annotated information from CAIDAC can be retrieved in order to provide different results, through examples taken from the study of disagreement in Catalan that was presented above. First of all, we look at the main pragmatic tags that were used in the 
corpus, that is, the ones that define the sequences of agreement and disagreement. Since the corpus under study is made up of three sub-corpora, the results are presented separately across these datasets:

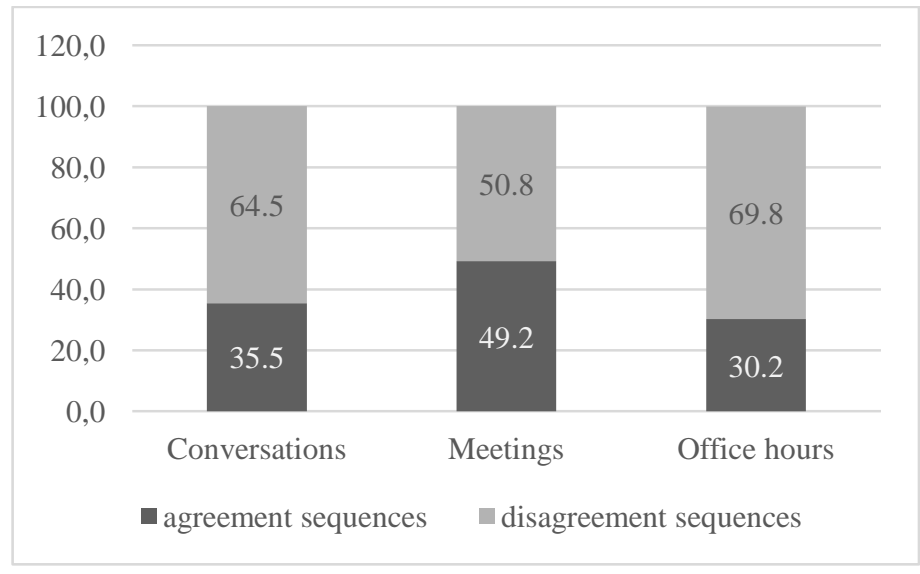

Fig. 3 Sequences of agreement and disagreement

Figure 3 shows that the sequences of disagreement clearly outnumber those of agreement in office hours and conversations, but are evenly matched in meetings. In the case of office hours, this is due to the conflictive nature of the samples that make up this subcorpus, where students try to prove to the professors that their assignments deserve a higher mark than the one they were given. Meanwhile, in the case of conversations, disagreement can be understood as a form of socialising: its appearance is proof of the close relationship shared by the speakers. Finally, in meetings there are more instances of agreement sequences because everything must be discussed and agreement must be verbally given in order to move to the next issue, even when all the participants share the same point of view (Ehlich and Wagner 1995).

An important point must be made in relation to the importance of the use of appropriate statistical methods to validate the findings of this kind of research. Figure 3 shows us descriptive statistics in percentages but as a researcher, it is important to make sure that the differences between categories in the quantitative analysis are statistically significant, that is, that they are not due to chance, but to the fact that the elements that are being compared are actually different. Though there are a number of methods that available for corpus analysis, generalised linear mixed-effects models (GLMMs) was used here, as recommended by Gries (2015) and Jaeger (2008). GLMMs can deal with the high complexity and inherent features of spoken corpora, such as an unbalanced design. Basically, they offer "sophisticated ways to partial out, or accommodate, for instance, speaker- or item-specific effects (or other effects extraneous to the specific research question" (Gries: 2015: 97). This means that if there is a specific feature that is particularly salient in the results, this model can prove whether this salience is actually real, i.e. statistically significant, or is a result derived of a single speaker or a single sample instead. For example, in figure 3, the high percentage of agreement sequences in meetings could simply be due to the fact that a particular long sample contains a high number of agreement head acts, which would mean that the difference between genres is not statistically significant. The use of GLMMs reveals that in this case only the differences between meetings and office hours are statistically significant, that is, they are a result of the different discourse genre to which they belong. In other words, disagreement sequences are 
less likely to appear in a meeting than agreement sequences, whereas in office hours the opposite pertains. As for the difference in the results between meetings and conversations, GLMMs reveal that it is not significant and should be attributed to other factors.

After retrieving the general results for the macro category created to establish the sequences of agreement and disagreement, figure 4 displays a much more specific result: the differences in the use of the three more frequent types of direct disagreement made by friends and family members, two roles that can only be found in the casual conversations and that fit into the socialising and intimate type of relationship. These three types of direct disagreement, drawn from previous studies on disagreement and the analysis of the corpus, are contrast, in which the speaker expresses the opposite polarity of the utterance that gave rise to the disagreement ("she got scared" / "no, she didn't"); correction, ${ }^{4}$ where the speaker changes a specific part of the previous utterance or verbalises a different opinion ("this isn't too sweet" / "well, it is quite sweet"); and, finally, objection, where the speaker uses an adversative conjunction, usually but, to point out a problematic aspect of the previous utterance ("it's really dark" / "but you can see it really well!").

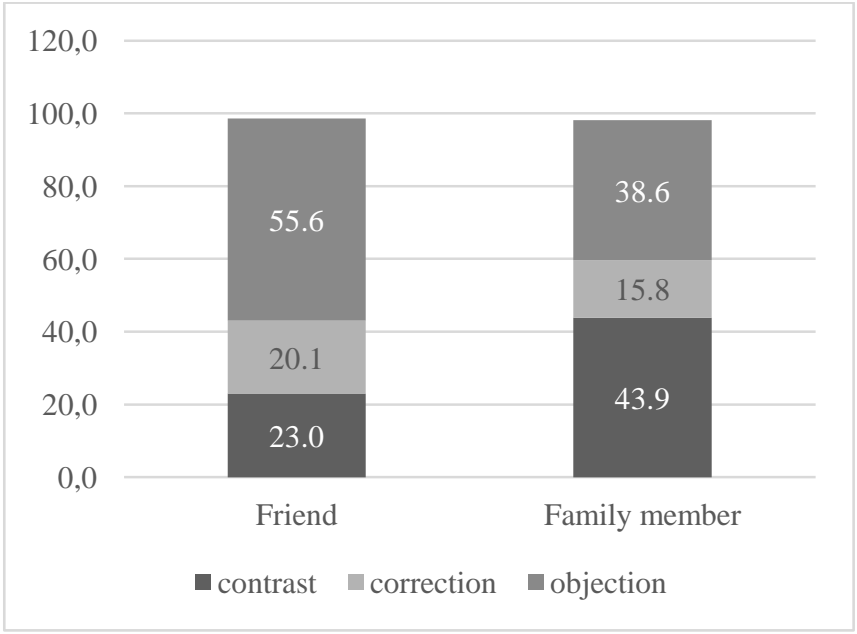

Fig. 4 Frequent types of direct disagreement used by friends and family members

As opposed to the general information on discourse genres shown in figure 3 , in this case the results are much more specific, since they compare the use of these strategies according to the two speaker roles found in conversations. The results reveal statistically significant differences regarding the most widelyused manifestation of direct disagreement for each role. While friends favour objections made by an initial but ("we only needed one each" / "but they were so small!"), which is the mostly-used strategy in the three discourse genres in general, family members seem to prefer the undisguised confrontation of contrasts, which directly negate what their interlocutor said ("that's not true, it wasn't me" / "Yes, it was you"). This difference could be attributed to the different trust that exists between close family members (which in the corpus are parents, adult children and siblings) and friends, which explains why family members say exactly the opposite ("dad never does the washing up" / "yes, I do!") while the friends focus only on a specific aspect of what their interlocutor said to express their disagreement. These disagreeing turns do not give rise to any conflict with the other participants, as proved by the lack of a negative reaction in the following turns. These results fall in line with Clancy's (2011) results regarding family 
discourse: he establishes that family members are direct because their relationship is fixed and cannot be changed, and this differs from the relationship between friends, which must be maintained through mutual efforts.

In this study of agreement and disagreement, the annotation included not only pragmatic categories, but also concepts from conversation analysis, since disagreement has been frequently studied within this paradigm. Figure 5 shows some of the results that can be obtained by adding these phenomena, particularly overlaps and interruptions, in the annotation:

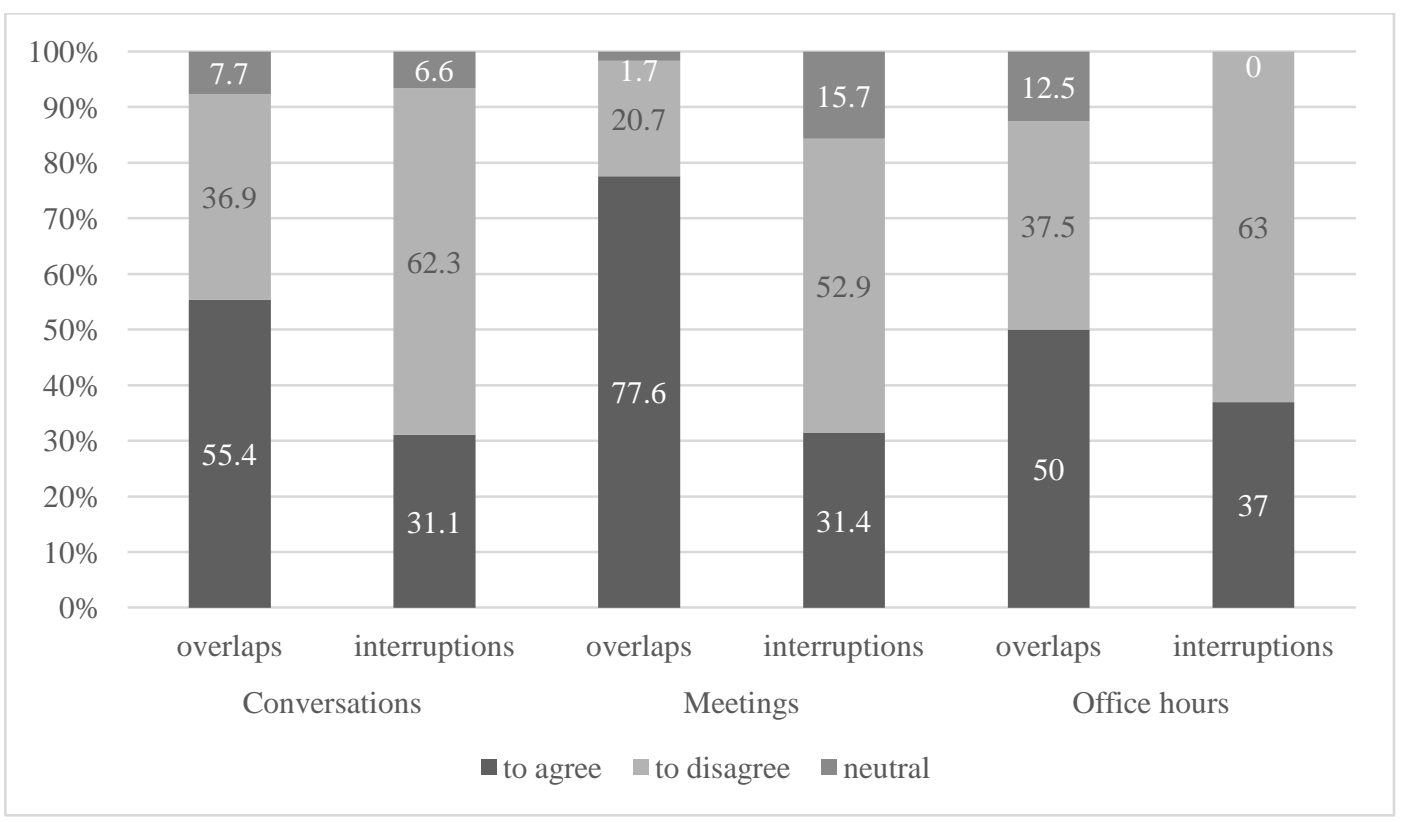

Fig. 5 Overlaps and interruptions in the three discourse genres

As shown in figure 5, overlaps mostly happen when speakers want to express agreement, because they voice it out before their interlocutors have finished their turns, but the percentage is much higher in meetings than in the other two genres. This can be due to the fact that, as it has been previously stated, meetings demand constant agreement from participants, a fact that significantly increases the appearance of agreement sequences and, therefore, of overlaps. Concerning the structure of the overlaps, there are clear differences that stem from their orientation towards agreement or disagreement. When the occurrences of overlap are viewed closely using concordance lines, they show that short response tokens, such as sí 'yes', clar 'of course' or vale 'ok', are usually used to agree and they normally overlap with the last syllables uttered by the previous speaker, so both turns end simultaneously. Overlaps used to disagree, on the other hand, are much longer (for example, they start with a but followed by a long stretch of talk that focuses on the "flawed" aspect of the interlocutor's position) and they carry on once the previous speaker has finished, since they ultimately seek to take over the floor in order to fully express their point. ${ }^{5}$ These results reflect the very nature of disagreement, which has a much more complex structure than agreement (Milà-Garcia 2017). Regarding interruptions, the trend is the opposite as for overlaps: they are mostly used to disagree. Even though they are much less frequent than overlaps, results clearly show that interruptions carry a clear purpose, which is to prevent the speaker who holds the floor from continuing their reasoning. These results could, in turn, be broken down even further, for example 
by singling out different speakers by role, sex, age, etc., or by studying which kind of disagreement is used to interrupt.

Finally, the last example was chosen to show how researchers can combine different layers of annotation in order to obtain very specific results. In this sense, figure 6 shows the relationship between speaker status and the degree of mitigation in disagreement:

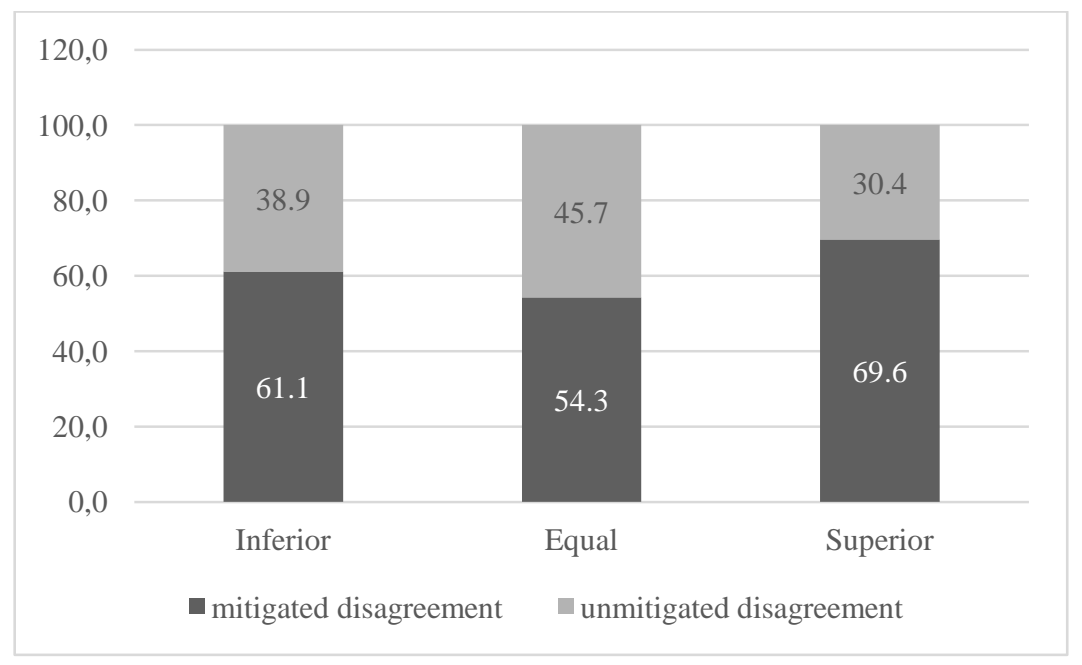

Fig. 6 Mitigation in disagreement according to the status of the speakers

Mitigation in disagreement can take two different forms. On the one hand, the illocutionary force of direct disagreement can be reduced by using different kinds of mitigators. On the other hand, all the instances of indirect disagreement are considered to be intrinsically mitigated, because their illocutionary force is implied, but not explicit as in direct disagreement. The mitigating value of indirectness was first established by Brown and Levinson (1987), and although it has been challenged in informal contexts (Terkourafi 2011), ${ }^{6}$ indirect acts are usually included in mitigation taxonomies (Albelda and Cestero 2011). As shown in figure 6, speakers of equal status present a balanced use of mitigation and unmitigated direct disagreement. The difference is greater for speakers of inferior status, whereas mitigated disagreement clearly dominates in the disagreement pronounced by speakers with superior status. These fine-grained results are essential in order to properly interpret the general results obtained in the analysis of office hours as a discourse genre, since they derive from the combination of the performance of two speakers with very different status that behave and express themselves differently. As it seems, professors mitigate their disagreement to a greater extent than students despite their superior status, which is probably due to their pedagogical role as enablers and guides. However, the multi-layered and detailed annotation that was applied to the corpus can provide even more specific information. For example, researchers could explore whether professors and students prefer to mitigate their disagreement with mitigators or via indirect strategies, and, furthermore, what kinds of mitigators were used by the two groups of speakers.

The results presented in this section are just a few examples of the different ways that data can be recovered from a pragmatically annotated corpus. In order to do so, researchers must take the time to 
annotate all the information related to the situational context that is necessary to carry out proper pragmatic analysis, the possibilities that the resulting corpus will offer increase exponentially and beyond the quantitative dimension. If this kind of information is then combined with an elaborate taxonomy devised for the study of a specific speech act or pragmatic phenomenon, the results will procure a very detailed picture of the way they are expressed and even of the influence that politeness and face can have in the way they are manifested in different situations.

\section{Final remarks}

Compiling a corpus for a specific use presents many advantages, but there is a major drawback that must be acknowledged and overcome: it demands an important time investment. Not only must the samples be collected, but they must also be transcribed and annotated with a taxonomy designed for a specific purpose. In this study, five layers of annotation were designed and applied to the corpus, which allowed the researcher to combine the study of specific pragmatic elements (speech acts) with macro aspects such as sequences, samples, speakers and even with elements from conversation analysis. A detailed annotation scheme offers the chance to approach the data from different perspectives as well as to obtain raw counts for a quantitative analysis, and it can include not only basic sociolinguistic information (age, sex, education), but also aspects about the situational context. Due to its complexity, applying this type of taxonomy or classification can be time-consuming. However, it is as a worthy investment, since "[i]n addition to the richness of the results, and the surprises they hold, the research creates a really useful and reusable resource through tagging and coding. Pragmatic tagging, while time-consuming and challenging, is the holy grail for this field" (Clancy and O'Keeffe 2015: 251).

The aim of this paper was to present a successful sample of the results that can be obtained by applying manual pragmatic annotation. It aimed to prove that, however complex the taxonomy or long the sample, once the preparation is complete and the corpus is ready to be exploited, researchers can be certain that all the time and effort will bear fruitful and grounded results. It showed that, despite its limitations, it is possible to carry out detailed corpus-based function-to-form analysis through the meticulous pragmatic coding of a small sample. Moreover, this paper offered an example of how specific one-to-one searches of pragmatic functions can become, since in this case they focus not only on speech acts in general, but on their specific realisation through the use of head acts, mitigators, aggravators and other categories. In this sense, it makes a significant contribution to the current researched aimed "to arrive at enhanced understandings of the value and limitations of methodologies within the area of pragmatics" (O'Keeffe forthcoming).

Designing and applying such a complex taxonomy is certainly challenging, but researchers never start from scratch: in the case of agreement and disagreement, as well as in many other speech acts, there are many existing taxonomies that have already been published and refined, and those can therefore provide a starting point from which to build an appropriate taxonomy, which must be applied through careful corpus observation and contextualised analysis. The same is the case with mitigation, which has been 
studied extensively in the literature related to politeness and face. Although in some cases it might not be possible to adapt existing taxonomies and classifications to specific languages or cultures, it is important that researchers make use of all the work that has been done before whenever possible, instead of starting anew each time a pragmatic study is proposed. In this sense, corpus pragmatics can benefit greatly from all the research that has been carried out previously in qualitative analyses. Moreover, it can be used to demonstrate the validity of these qualitative results by testing them with larger samples of naturally occurring data, as opposed to the limited scope provided by small samples or data obtained from discourse completion tests or role plays.

\section{Conflict of interest}

The corresponding author states that there is no conflict of interest.

\section{References}

Adolphs, S., \& Knight, D. (2010). Building a spoken corpus: what are the basics?. In A. O’Keeffe, \& M. McCarthy (Eds.), The Routledge Handbook of Corpus Linguistics (pp. 38-52). Oxford: Routledge.

Aijmer, K., \& Rühlemann, C. (Eds.) (2015). Corpus Pragmatics: a Handbook. Cambridge: Cambridge University Press.

Albelda, M., \& Cestero, A. M. (2011). De nuevo, sobre los procedimientos de atenuación lingüística. Español actual, 96, 9-40.

Alturo, N., Bladas, Ò., Payà, M., \& Payrató, L. (2004). Corpus oral de registres. Materials de treball. Barcelona: Publicacions i Edicions de la Universitat de Barcelona.

Archer, D. (2005). Historical Sociopragmatics: Questions and Answers in the English Courtroom (16401760). Amsterdam: John Benjamins.

Archer, D., Culpeper, J., \& Davies, M. (2008). Pragmatic annotation. In A. Lüdeling, \& M. Kytö (Eds.), Corpus Linguistics: an International Handbook (pp. 613-642) Berlin: de Gruyter.

Atelsek, J. (1981). An Anatomy of Opinions. Language in Society, 10(2), 217-225.

Blum-Kulka, S., House, J., \& Kasper, G. (Eds.) (1989). Cross-Cultural Pragmatics: Requests and Apologies. Norwood: Ablex.

Brenes Peña, E. (2011). Actos de habla disentivos: identificación y análisis. Sevilla: Alfar.

Brown, P., \& Levinson, S. C. (1987). Politeness. Some Universals in Language Usage. Cambridge: Cambridge University Press.

Clancy, B. (2011). Complementary perspectives on hedging behaviour in family discourse: The analytical synergy of variational pragmatics and corpus linguistics. International Journal of Corpus Linguistics 16(3), 371-390.

Clancy, B., \& McCarthy, M. (2015). Co-constructed turn-taking. In K. Aijmer, \& C. Rühlemann (Eds.), Corpus Pragmatics (pp. 430-453). Cambridge: Cambridge University Press.

Clancy, B., \& O’Keeffe, A. (2015). Pragmatics. In D. Biber, \& Reppen, R. (Eds.), The Cambridge Handbook of English Corpus Linguistics (pp. 235-251). Cambridge: Cambridge University Press.

Crowdy, S. (1993). Spoken corpus design. Literary and Linguistic Computing, 8(4), 259-265. 
Culpeper, J., \& Archer, D. (2008). Requests and directness in Early Modern English trial proceedings and play-texts, 1640-1760. In A. H. Jucker, \& Taavitsainen, I. (Eds.), Speech Acts in the History of English (pp. 45-84). Amsterdam: John Benjamins.

Drew, P., \& Heritage, J. (Eds.) (1992). Talk at Work: Interaction in Institutional Settings. Cambridge: Cambridge University Press.

Du Bois, J. (1991). Transcription design principles for spoken discourse research. Pragmatics, 1, 71-106.

Dwyer, J. (1993). Business Communication Handbook. Sydney: Pearson Australia.

Edmondson, W. (1981). Spoken Discourse. A Model for Analysis. London: Longman.

Eggins, S., \& Slade, D. (1997). Analysing Casual Conversation. London: Cassell.

Ehlich, K., \& Wagner, J. (Eds.) (1995). The Discourse of Business Negotiation. Berlin: de Gruyter.

Flowerdew, L. (2004). The argument for using English specialized corpora to understand academic and professional Language. In U. Connor, \& T. A. Upton (Eds.), Discourse in the Professions. Perspectives from Corpus Linguistics (pp. 11-34). Amsterdam: John Benjamins.

García McAllister, P. (2015). Speech acts: a synchronic perspective. In K. Aijmer \& C. Rühlemann (Eds.). Corpus Pragmatics: a Handbook (pp. 29-51). Cambridge: Cambridge University Press.

Geluykens, R., \& Kraft, B. (2008). The use(fulness) of corpus research in cross-cultyural pragmatics: Complaining in intercultural service encounters. In J. Romero-Trillo (Ed.), Pragmatics and Corpus Linguistics. A Mutualistic Entente (pp. 93-117). Berlin: de Gruyter.

Gries, S. T. (2015). The most under-used statistical method in corpus linguistics: multi-level (and mixedeffects) models. Corpora, 10(1), 95-125.

Chang, W.-L. M., \& Haugh, M. (2013). 'Face' in Taiwanese business interactions: from emic concepts to emic practices. In Y. Pan, \& D. Z. Kadar (Eds.), Chinese discourse and interaction (pp. 126-150). Bristol: Equinox Publishing.

Holmes, J., Stubbe, M. (2003). Power and Politeness in the Workplace: A Sociolinguistic Analysis of Talk at Work. Harlow: Pearson.

Jaeger, T. F. (2008). Categorical data analysis: away from ANOVAs (transformation or not) and towards logit mixed models. Journal of Memory and Language, 59(4), 434-446.

Jautz, S. (2008) Gratitude in British and New Zealand radio programmes: Nothing but gushing? In K. Schneider, \& A. Barron (Eds.), Variational pragmatics: A focus on regional varieties in pluricentric languages (pp. 141-178). Amsterdam: John Benjamins.

Jucker, A. H. (2013). Corpus pragmatics. Handbook of Pragmatics. 17, 1-18.

Kallen, J., \& Kirk, J. M. (2012). SPICE-Ireland: A User's Guide. Belfast: Cló Ollscoil na Banríona.

Kasper, G., \& Dahl, M. (1991). Research methods in interlanguage pragmatics. Studies of Second Language Acquisition, 13, 149-169.

Kirk, J. M. (2016). The Pragmatic Annotation Scheme of the SPICE-Ireland Corpus. International Journal of Corpus Linguistics, 21(3), 299-322.

Koester, A. (2010). Workplace Discourse. London: Continuum.

Kohnen, T. (2015). Speech acts: a diachronic perspective. In K. Aijmer, \& C. Rühlemann (Eds.), Corpus Pragmatics: a Handbook (pp. 52-83). Cambridge: Cambridge University Press. 
Kotthoff, H. (1993). Disagreement and concession in disputes: on the context sensitivity of preference structures. Language in Society, 22, 193-216.

Leech, G. (1993). Corpus annotation schemes. Literary and linguistic computing, 8(4), 275-281.

Levinson, S. C. (1979). Activity types and Language. Linguistics, 17, 365-399.

Locher, M. A. (2004). Power and Politeness in Action. Disagreements in Oral Communication. Berlin / New York: de Gruyter.

Locher, M. A., \& Watts, R. J. (2005). Politeness Theory and Relational Work. Journal of Politeness Research, 1(1), 9-33.

Ballester, A., Marcos-Marín, F. A., \& Santamaría, C. (1993). Transcription Conventions used for the Corpus of Spoken Contemporary Spanish. Literary and Linguistic Computing, 8(4), 283-292.

McCarthy, M. (1998). Spoken language and Applied Linguistics. Cambridge: Cambridge University Press.

McCarthy, M., \& O’Keeffe, A. (2008). Corpora and the study of spoken Language. In A. Lüdeling, K. Merja, \& T. McEnery (Eds.), Handbook of Corpus Linguistics (1-16). Berlin: de Gruyter.

McEnery, T., Xiao, R., \& Tono, Y. (2006). Corpus-based Language Studies: An Advanced Resource Book. New York: Routledge.

Milà-Garcia, A. (2017). L'acord i el desacord en català en tres gèneres discursius: anàlisi sociopragmàtica [Agreement in disagreement in Catalan in three discourse genres: a sociopragmatic analysis]. $\mathrm{PhD}$ dissertation. Barcelona: Pompeu Fabra University.

Muntigl, P., \& Turnbull, W. (1998). Conversational structure and facework in arguing. Journal of Pragmatics, 29(3), 225-256.

O'Donnell, M. (2008). Demonstration of the UAM CorpusTool for text and image annotation. Proceedings of the ACL-08:HLT Demo Session. Columbus, Ohio, June 2008. Association for Computational Linguistics. 13-16.

O’Keeffe, A. (forthcoming). Corpus-based function-to-form approaches. In A. H. Jucker, K. P. Schneider, \& W. Bublitz (Eds.). Methods on Pragmatics. Berlin: Mouton de Gruyter.

O'Keeffe, A., \& Walsh, S. (2012). Applying corpus linguistics and conversation analysis in the investigation of small group teaching in higher education. Corpus Linguistics and Linguistic Theory, 8, 159-181.

Payrató, L., \& Alturo, N. (2002). Corpus oral de conversa col-loquial. Materials de treball. Barcelona: Publicacions de la Universitat de Barcelona.

Pomerantz, A. (1984). Agreeing and disagreeing with assessments: Some features of preferred/dispreferred turn shapes. In J. M. Atkinson, \& J. Heritage (Eds.). Structures of Social Action (pp. 57-101). Nueva York: Cambridge University Press.

Rees-Miller, J. (2000). Power, severity, and context in disagreement. Journal of Pragmatics, 32(8), 10871111.

Romero-Trillo, J. (Ed.) (2008). Pragmatics and Corpus Linguistics. A Mutualistic Entente. Berlin: de Gruyter.

Ronan, P. (2015). Categorizing expressive speech acts in the pragmatically annotated SPICE Ireland corpus. ICAME Journal, 39, 25-45. 
Rühlemann, C. (2007). Conversation in Context. London: Continuum.

Santamaría-García, C. (2005). La negociación de acuerdo en la conversación coloquial. Estudio contrastivo español-inglés. PhD dissertation. Madrid: Universidad Complutense de Madrid. Available at <http://eprints.ucm.es/5477/>.

Santamaría-García, C. (2011). Bricolage assembling. CL, CA and DA to explore agreement. International Journal of Corpus Linguistics, 16(3), 345-370.

Schegloff, E. A. (2007). Sequence organization in interaction: a primer conversation analysis. Cambridge: Cambridge University Press.

Searle, J. (1976). A Classification of Illocutionary Acts. Language in Society, 5(1), 1-23.

Scollon, R., \& Scollon, S. W. (1995). Intercultural Communication: a Discourse Approach. Oxford: Blackwell.

Scollon, R., Scollon, S. W., \& Jones, R. H. (2012). Intercultural Communication. a Discourse Approach. 3rd ed. Malden: Wiley-Blackwell.

Scott, S. (2002). Linguistic feature variation within disagreements: an empirical investigation. Text, 22(2), 301-328.

Sidnell, J. (2010). Conversation Analysis: an Introduction. London: Wiley-Blackwell.

Terkourafi, M. (2011). «The puzzle of indirect speech». Journal of Pragmatics 43 (11). 2861-2865.

Vaughan, E., \& Clancy, B. (2013). Small corpora and pragmatics. In J. Romero-Trillo (Ed.). Yearbook of Corpus Linguistics and Pragmatics 2013 (pp. 53-73). Dordrecht: Springer.

Walsh, S., Morton, T., \& O’Keeffe, A. (2011). Analysing university spoken interaction. A CL/CA approach. International Journal of Corpus Linguistics, 16, 325-344.

Weisser, M. (2003). SPAACy: A semi-automated tool for annotating dialogue acts. International Journal of Corpus Linguistics, 8(1), 63-74.

Weisser, M. (2015). Speech act annotation. In K. Aijmer \& C. Rühlemann (Eds.), Corpus Pragmatics: $a$ Handbook (pp. 84-114). Cambridge: Cambridge University Press.

Yang, S. (2014). Interaction and codability: a multi-layered analytical approach to discourse markers in teacher's spoken discourse. In J. Romero-Trillo (Ed.), Yearbook of Corpus Linguistics and Pragmatics 2014 (pp. 291-314). Dordrecht: Springer.

\section{Appendix 1: exemplification of the layers of annotation}

All the tags are shown in italics and correspond to the annotation of the underlined fragments. The direction of the arrow shows the different level of specificity of a tag: the researcher must always reach the most specific level, but any level can be recovered for the analyses.

\section{Appendix 1.1: Situational information}

Global tag applied to the whole sample, in this case, C5: conversation [genre], c5 [sample], socialising [interaction type], 4 [speakers], night [time], restaurant [place], equal [status], high [affective involvement], regular [contact frequency], voluntary [contact reason]. 
Appendix 1.2: Speaker information

C5 [11]

MAF: $\quad$ This egg is over-cooked.

female [gender], 25 [age], further education [level of education], friend [role], middle [status relations]

EAF: It depends on how you like it, though. female [gender], 25 [age], further education [level of education], friend [role], middle [status relations]

MAF: It should be almost raw! female [gender], 25 [age], further education [level of education], friend [role], middle [status relations]

EAF: $\quad$ Yeah, in order to make it -- yeah. female [gender], 25 [age], further education [level of education], friend [role], middle [status relations]

\section{Appendix 1.3: Sequence information}

Global tag applied to sequence 11 from conversation 5: disagreement sequence.

\section{Appendix 1.4: Interactional information}

\section{C5 [11]}

MAF: This egg is over-cooked.

EAF: $\quad(1,6)$ It depends on how you like it, though. $\quad$ gap $\rightarrow$ external

MAF: (2) It should be almost raw! gap $\rightarrow$ external

EAF: $\quad \ldots$ Yeah, in order to make it -- yeah. $\quad$ gap $\rightarrow$ external

C5 [15]

EAF: Maybe I'd rather do that than $\quad$ overlap $\rightarrow$ speaker 1

MAF: $\underline{\text { Yes. }}$

overlap $\rightarrow$ speaker $2 \rightarrow$ to agree

EAF: dessert.

MAF: Yes.

\section{Appendix 1.5: Pragmatic information}

C5 [11]

MAF: This egg is over-cooked.

EAF: $(1,6)$ It depends on how you like it, though.

MAF: (2) It should be almost raw!

EAF: $\quad \ldots$ Yeah, in order to make it -- yeah.

$$
\begin{aligned}
& \text { initiation } \rightarrow \text { assessment } \\
& \text { head act } \rightarrow \text { disagreement } \rightarrow \text { hint } \\
& \text { supportive move } \rightarrow \text { aggravator } \rightarrow \text { reiteration } \\
& \text { closing } \rightarrow \text { acceptance }
\end{aligned}
$$

C5 [35]

NAF: But this boat thing is plain silly .. what?

EAF: Well, but each person -- there are people who like that!

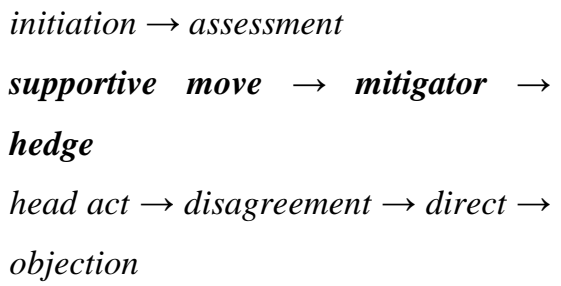


NAF: $\quad$ But we join all the stag parties there --

MAF: $\quad$ Yes, that's true.

NAF: on the boat?

EAF: $\quad$ No, no, I know. supportive move $\rightarrow$ aggravator $\rightarrow$ reiteration

head act $\rightarrow$ agreement $\rightarrow$ direct $\rightarrow$ strong

other $\rightarrow$ continuation

closing $\rightarrow$ acceptance

\footnotetext{
${ }^{1}$ The need to include more contextual information was previously pointed out in Santamaría-Garcia (2011).

${ }^{2}$ This denomination changes according to the author: Levinson (1979) considered them activity types, while Rühlemann (2007) called them situation types.

${ }^{3}$ Even though both Catalan and Spanish are official languages in Catalalonia, speakers usually favour the use of one over the other in their daily lives: the speakers in this study use Catalan in almost every context.

${ }^{4}$ Correction has been included as a form of disagreement by previous studies such as Kangasharju (2002) and Brenes Peña (2011).

${ }^{5}$ This type of observation could be very relevant in the general discussion about (dis)agreement and preference in conversation analysis. The relationship between agreement and preferred second pair parts, and disagreement and dispreferred second pair parts, was put forward by Pomerantz (1984), but it has since then been challenged by different authors, such as Kotthoff (1993) and Santamaría-García (2011).

${ }^{6}$ See Milà-Garcia (2017) for an analysis of the different values that indirect disagreement can adopt according to the discourse genre.
} 